\title{
Conteúdo de Geociências em Livros Didáticos de Ciências do Ensino Fundamental I: Identificando a Presença e os Temas Abordados
}

\author{
Geosciences Content in Science Textbooks for Elementary School I: \\ Identifying its Presence and the Addressed Themes
}

\author{
iD Cláudia Patrícia Araújo e Silva' \\ Daquel Franco de Souza ${ }^{2}$
}

\begin{abstract}
'Universidade Estadual de Campinas (UNICAMP), Instituto de Geociências, Programa de Pós-Graduação em Ensino e História de Ciências da Terra, Campinas, SP, Brasil. Autora correspondente: c264271@dac.unicamp.br

${ }^{2}$ Universidade Federal do Rio Grande do Norte (UFRN), Centro de Ciências Exatas e da Terra, Departamento de Geologia, Natal, RN, Brasil.
\end{abstract}

Resumo: Diversos pesquisadores apontam para a importância do conteúdo de Geociências na construção do currículo da escola básica. Apesar disso, ao longo das últimas décadas este conteúdo foi diminuído do currículo escolar, estando atualmente presente principalmente nas disciplinas de Ciências e Geografia, no Ensino Fundamental. Pesquisas nesta área concentram esforços em compreender as Geociências, sobretudo, no Ensino Fundamental II e Ensino Médio. Esta pesquisa, entretanto, buscou compreender a presença dos conteúdos de Geociências dentro das unidades temáticas propostas pela Base Nacional Comum Curricular (BNCC), no Ensino Fundamental I, utilizando para isso manuais didáticos de Ciências adotados pelo Plano Nacional do Livro Didático para a rede municipal de ensino de Natal. Para quantificação destes conteúdos, descreve-se uma metodologia de contagem utilizando-se incrementos de $1 / 4$ de página. Foi constatado que os conteúdos de Geociências estão significativamente presentes neste ciclo do ensino, distribuídos em todos os manuais analisados e em todas as unidades temáticas propostas pela BNCC.

Palavras-chave: Educação básica; Conteúdos do livro didático; Ensino de geociências; Base nacional comum curricular.

Abstract: A number of researchers point out the importance of Geosciences content in the construction of the elementary school curriculum. However, over the last decades this content has been reduced in the school curriculum and is currently present mainly in the subjects of Sciences and Geography in Elementary School. Studies in this area have focused on understanding geosciences, especially in elementary and high school. This research, however, sought to understand the presence of geosciences content within the thematic units proposed by the Common National Curriculum Base (BNCC) in Elementary School I by using, for this purpose, didactic Science manuals adopted by Plano Nacional do Livro Didático 2019 for the municipal education network of a Brazilian city. To quantify this content, a counting methodology is described using $1 / 4$-page increments. It was found that geosciences content is significantly present in this cycle of education, distributed in all analyzed manuals and in all thematic units proposed by BNCC.

Keywords: Basic education; Textbook content; Geosciences teaching; Common national curriculum base.

Recebido em: 08/10/2019

Aprovado em: 26/05/2020 


\section{Introdução}

O livro didático constitui uma importante ferramenta utilizada para promover o ensino no contexto escolar. Segundo Carvalho Neto (2015), por se tratar de um dos principais mediadores do processo de ensino e aprendizagem, este material interfere diretamente no trabalho pedagógico já que, muitas vezes, é o único recurso do qual o professor dispõe como auxílio à sua prática docente. Carneiro, Santos e Mól (2005) trazem que essa centralidade confere ao livro didático estatuto e funções privilegiadas na medida em que é por meio dele que o professor organiza, desenvolve e avalia seu trabalho pedagógico de sala de aula. Silva (2012) reforça que a importância do livro didático para muitos professores vai além de sua função como ferramenta didática, sendo muitas vezes utilizado como fonte de consulta pessoal dos professores, tornando-se responsável pela informação e formação destes.

Desde que foi publicada em 2017, a Base Nacional Comum Curricular (BNCC) "[...] define o conjunto orgânico e progressivo de aprendizagens essenciais que todos os alunos devem desenvolver ao longo das etapas e modalidades da Educação Básica" (BRASIL, 2017). Fundamentada na Constituição (BRASIL, 1988), nos Parâmetros Curriculares Nacionais (PCN) (BRASIL, 1997) e na Lei de Diretrizes e Bases da Educação Nacional (LDB, lei n 9.394/1996) (BRASIL, 1996), a BNCC é referência nacional para formação dos currículos, norteando os conteúdos que devem ser abordados dentro dos livros didáticos destinados ao ensino básico, distribuindo-os em unidades temáticas, competências e habilidades.

Por ter esse caráter unificador do ensino, é válida a preocupação de que a adoção da BNCC exclua dos conteúdos aqueles que são referentes às individualidades nas mais diversas esferas, como as particularidades sociais e espaciais de cada escola, levando-se em conta a pluralidade de contextos nas mais diversas regiões do país. Frente a isso, a BNCC carrega aspectos previstos na LDB que estabelece, em seu Art. 26, que a Base deve ser "[...] complementada, em cada sistema de ensino e em cada estabelecimento escolar, por uma parte diversificada, exigida pelas características regionais e locais da sociedade, da cultura, da economia e dos educandos" (BRASIL, 1996).

Nesse cenário, insere-se o conteúdo de Geociências. Ao longo das últimas décadas, as Geociências foram progressivamente retiradas do currículo da Educação Básica brasileira estando, atualmente, restrita às disciplinas de Geografia e Ciências, no Ensino Fundamental (BACCI; BOGGIANI, 2015; CARNEIRO; TOLEDO; ALMEIDA, 2004; COMPIANI, 1996; GUIMARÃES, 2004).

Contudo, alguns estudiosos dedicam suas pesquisas a demonstrar a importância que estes conteúdos possuem mesmo na educação básica, a exemplo de Carneiro, Toledo e Almeida (2004) que elencaram dez motivos para a inclusão de temas de Geologia na educação básica, enfatizando também a relevância do estudo das Geociências para compreensão da dinâmica ambiental e construção de uma educação ambiental mais sólida. Bacci (2015, p. 129) complementa a importância dos conhecimentos geocientíficos no ensino básico ao afirmar que estes podem "[...] levar à promoção de mudanças de costumes, atitudes e valores que contribuam para a formação de indivíduos atuantes na realidade local e capazes de promover transformações no ambiente de forma consciente e planejada". Piranha e Carneiro (2009) apontam que um dos atributos singulares da geologia éconceber deforma sistêmica a entidade planetária e seus habitantes, além de reforçarem a importância do ensino-aprendizagem das Geociências a partir dos aspectos regionais, não limitando-se ao conteúdo e exemplos dos Livros Didáticos (LD), afirmando que o "[...] uso de informações geológicas de caráter regional 
e local constitui forte elo integrador da aprendizagem, convidando os alunos à reflexão, mostrando-Ihes a realidade do local onde vivem e estimulando a consciência reflexiva de cada um." (PIRANHA; CARNEIRO, 2009, p. 18). Assim, os elementos das Geociências são fortemente representativos do ambiente, tratam das diversas relações que os seres vivos estabelecem com o meio físico, e possuem também relevante interface com as questões ambientais.

Ao buscar pesquisas sobre os temas geocientíficos no Ensino Básico, foi observado que estes contemplaram preferencialmente o Ensino Fundamental II e o Ensino Médio (BERGQVIST; PRESTES, 2014; CARNEIRO; SIGNORETTI, 2008; COMPIANI, 1996, 2005; PEREZ; ANDRADE; RODRIGUES, 2015; PONTE; PIRANHA, 2018). Existe para tal fato uma razão: ao observar os objetivos dos PCN, verifica-se que é a partir do Ensino Fundamental II que se concentram mais objetos de ensino no que concerne às Geociências. O que foi observado por Bacci, Oliveira e Pommer (2009), entretanto, é que os conteúdos de Geociências são abordados também nos anos iniciais do Ensino Fundamental, embora alguns professores ainda não os identifiquem. Os autores acrescentam ainda que a "[...] falta de conhecimento específico dos temas, alguns bastante abstratos e distantes do cotidiano escolar, quando tratados em geral são desconexos, superficiais e apresentam grande dificuldade para os professores" (BACCl; OLIVEIRA; POMMER, 2009 p. 3448).

Diante disso, neste trabalho, optou-se pelos anos iniciais do Ensino Fundamental, também chamado de Ensino Fundamental I, buscando-se verificar e quantificar a presença dos conteúdos de Geociências neste ciclo do ensino dentro das unidades temáticas propostas pela BNCC (BRASIL, 2017), usando para isso os Manuais do Professor da disciplina de Ciências, utilizados na rede municipal de ensino de Natal, adotados pelo Plano Nacional do Livro Didático (PNLD) 2019. Foram escolhidos os livros da cidade de Natal por ser esta pesquisa parte de uma pesquisa mais abrangente na qual objetiva-se elencar quais conteúdos de Geociências podem ser trabalhados de melhor forma nos Referenciais Curriculares do município, documento que se encontra em fase de elaboração e que visa à complementação dos conteúdos, bem como oferecer suporte para formulação dos currículos escolares, levando-se em consideração as particularidades locais, de forma complementar à BNCC.

\section{Materiais e Métodos}

O percurso metodológico realizado durante a pesquisa é constituído por três etapas, a saber: pré-análise, quantificação do conteúdo Geociências e descrição e categorização do conteúdo Geociências como descrito na Figura 1 e nos tópicos seguintes.

Figura 1 - Etapas metodológicas realizadas durante a pesquisa

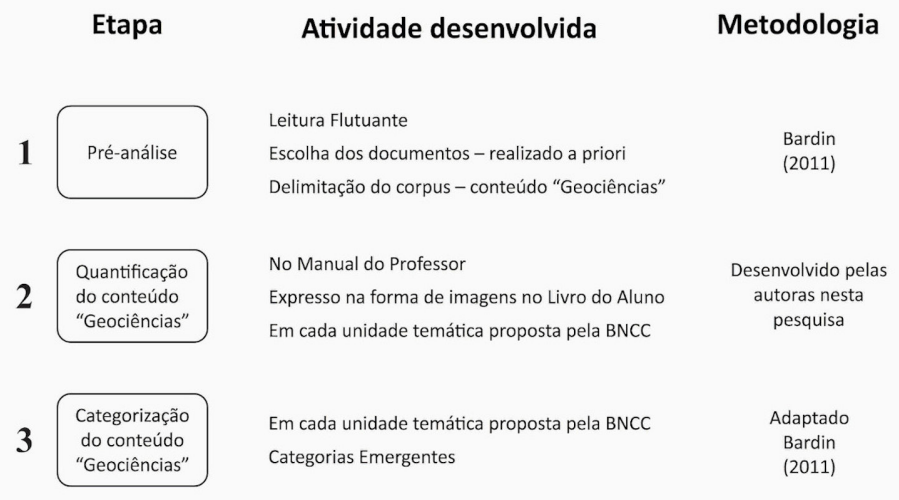

Fonte: elaborada pelas autoras. 


\section{Etapa 1: Pré-análise}

Foram seguidos elementos da Análise de Conteúdo de Bardin (2011); assima etapa inicial deste trabalho adotou as recomendações propostas pela autora para o que se configura uma etapa de pré-análise. A pré-análise é a etapa de organização; inicia com uma leitura flutuante do material, que consiste em "[...] estabelecer contato com os documentos a analisar e em conhecer o texto deixando-se invadir por impressões e orientações" (BARDIN, 2011, p. 126). Bardin (2011) sugere que seja feita a escolha dos documentos que, segundo a autora, pode ser a priori ou a posteriori; neste caso, a escolha foi feita pela escolha a priori e consiste nos Manuais do Professor da disciplina de Ciências, utilizados no Ensino Fundamental I, também chamado de anos iniciais, da rede pública municipal de ensino de Natal. Ao todo, são cinco Manuais do Professor, um para cada ano do Ensino Fundamental I. Os livros foram escolhidos pelo PNLD 2019, escolha unificada, tendo sido adotada a coleção Akpalô desenvolvida por Bigaiski e Sourient (2017). Por ter sido realizada escolha unificada, esta coleção deve ser utilizada em 49 escolas públicas da rede municipal do Ensino Fundamental I de Natal. Os livros têm um ciclo de atendimento quadrienal, entrando em vigor em 2019 e sendo utilizados até 2022. Optou-se pela utilização dos Manuais do Professor, pois estes trazem tanto um espaço do livro que corresponde à reprodução do Livro do Aluno (LA) em tamanho reduzido como um espaço que é destinado às Orientações Didáticas (OD) destinadas aos professores (Figura 2).

Figura 2 - Ilustração do Manual do Professor

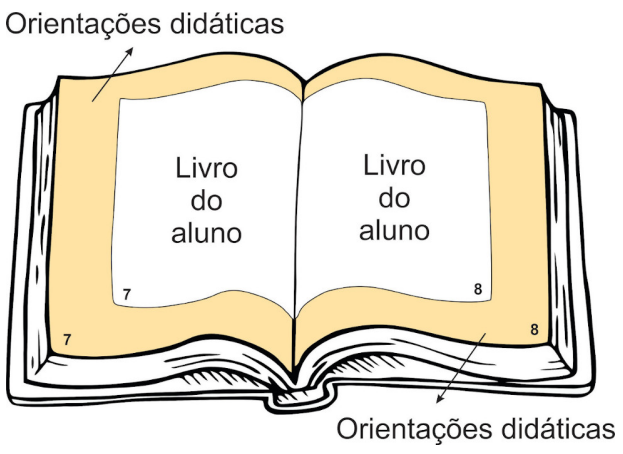

Nota: O manual do professor é composto por um espaço central que reproduz em tamanho reduzido o Livro do Aluno, e pelas Orientações Didáticas, dispostas nas partes laterais e inferiores de cada página.

Fonte: adaptada de Vexels (2020).

Tendo o universo dos documentos demarcado, o que se segue é a constituição de um corpus, sendo este o "[...] conjunto dos documentos tidos em conta para serem submetidos aos procedimentos analíticos" (BARDIN, 2011, p. 126). O nosso corpus foi constituído pelos conteúdos de Geociências nos livros analisados. Como conceito norteador para a delimitação desses conteúdos, utilizou-se a definição de Geociências conforme Compiani (2002):

[...] conteúdos de Geologia, Astronomia, Meteorologia, entre outros, que não constam como disciplina no currículo da escola fundamental, mas são abordados em Geografia e Ciências. Também incluímos muitos conteúdos de Geociências que antes eram apenas tratados na Geografia Física e que hoje estão também em Ciências, tais como: Pedologia, Climatologia etc. (COMPIANI, 2002, p. 29). 


\section{Etapa 2: Quantificação do conteúdo Geociências}

Esta etapa foi desenvolvida pelas autoras objetivando quantificar os conteúdos de Geociências presentes nos manuais analisados. A necessidade de descrever uma metodologia surgiu uma vez que trabalhos similares optaram por fazer a quantificação do conteúdo com base no número de páginas, a exemplo de Ruppenthal e Schetinger (2013); para o presente trabalho, a consideração por quantidade de página tornou-se insuficiente, uma vez que foram notadas páginas que contemplavam o conteúdo Geociências em toda sua área, enquanto outras páginas traziam o assunto apenas em um parágrafo ou imagem. Visando minimizar tal discrepância, para o cálculo estimado do conteúdo de Geociências dentro de cada Manual do Professor, os espaços do Livro do Aluno e das Orientações Didáticas foram subdivididos em unidades, aqui chamadas de incrementos de $1 / 4$ de página (conforme figura 3A e 3B), de modo similar ao realizado por Tomotani e Salvador (2017).

A Figura 3 ilustra a subdivisão do Livro do Aluno e das Orientações Didáticas em incrementos de $1 / 4$ de página, mostrando como foi realizada a contagem de incrementos representativa dos conteúdos de Geociências. Cabe ressaltar que se considerou o conteúdo expresso nas mais variadas formas, como em textos, imagens e exercícios. A contagem foi realizada conforme Figura 3C e 3D, por exemplo: no espaço destinado ao Livro do Aluno na página 11 (Figura 3C), contou-se 2 incrementos de Geociências, enquanto nas Orientações Didáticas desta mesma página contou-se 4 incrementos. Já a página 12 (Figura 3C), mostra que no Livro do Aluno não foi abordado conteúdo de Geociências, mas nas Orientações Didáticas contaram-se dois incrementos desses conteúdos. Já a página 13 (Figura 3D) ilustra uma situação na qual todo o espaço do Livro do Aluno e das Orientações Didáticas continha conteúdos de Geociências, sendo contabilizados assim 4 incrementos no LA e 4 incrementos na OD, assim sucessivamente.

Figura 3 - Subdivisão do Manual do Professor em Livro do Aluno e Orientações Didáticas exemplificando a contagem de incrementos
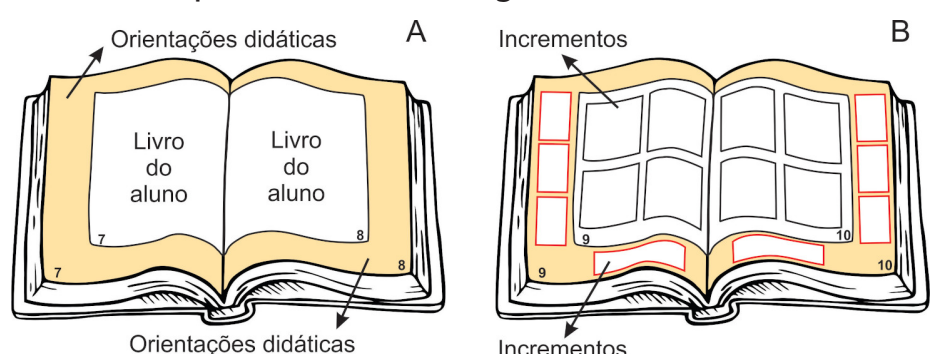

B
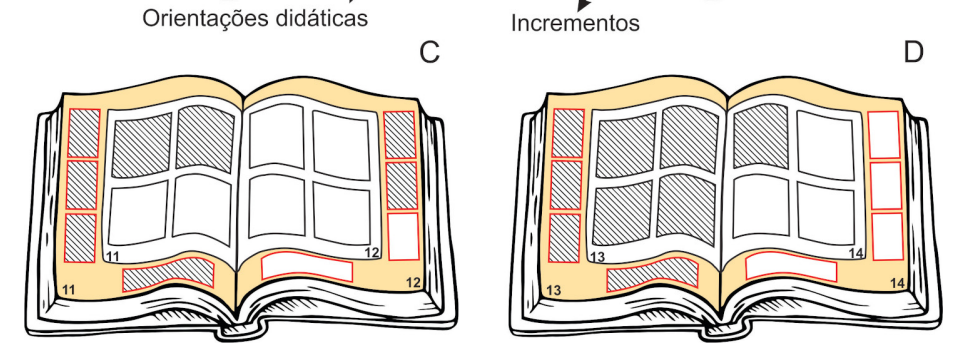

Nota: A: llustração representativa do Manual do Professor (Livro do Aluno + Orientações Didáticas). B: Subdivisão do Manual do Professor em incrementos de $1 / 4$ de páginas. C e D: exemplos da contagem de incrementos correspondentes à conteúdos de Geociências.

Fonte: adaptada de Vexels (2020). 
A quantificação dos conteúdos de Geociências foi feita em três fases que são descritas a seguir e podem ser também visualizadas de maneira sistemática na Figura 5 . Entretanto, para cálculo relativo da quantidade de incrementos de Geociências em cada uma dessas fases, foi necessário, primeiramente, quantificar o total de incrementos de cada manual, conforme mostrado na Figura 4. É importante destacar que da quantidade total de páginas do livro foram desconsiderados o sumário e as referências bibliográficas, por exemplo.

Figura 4 - Cálculo da quantidade de incrementos do Manual do Professor

Quantidade de incrementos no Manual do Professor

\begin{tabular}{|c|c|c|c|c|}
\hline $\begin{array}{l}\text { Livro do Aluno } \\
\text { (Incr LA) } \\
\text { 4x quantidade total de } \\
\text { páginas do livro }\end{array}$ & + & $\begin{array}{c}\text { Orientações Didáticas } \\
\text { (Incr OD) } \\
4 \text { x quantidade total de } \\
\text { páginas do livro }\end{array}$ & $=$ & $\begin{array}{l}\text { Manual do Professor } \\
\text { (Incr Manual) } \\
\text { 8x quantidade total de } \\
\text { páginas do livro }\end{array}$ \\
\hline
\end{tabular}

Fonte: elaborado pelas autoras.

A Fase 1 refere-se à quantificação dos conteúdos de Geociências presentes no Livro do Aluno e nas Orientações Didáticas, sendo que o somatório de ambos corresponde ao conteúdo de Geociências no Manual do Professor. Na Fase 2 tem-se a quantificação do conteúdo de Geociências que é expresso na forma de imagens. Como as imagens que remetiam a conteúdos de Geociências foram encontradas apenas dentro do Livro do Aluno, levou-se em consideração para a contagem das imagens apenas esse espaço. Por fim, a Fase 3 refere-se à quantificação dos conteúdos de Geociências nas Unidades Temáticas propostas pela BNCC para o ensino de Ciências do $1^{\circ}$ ao $5^{\circ}$ ano, sendo elas: Matéria e Energia, Vida e Evolução, e Terra e Universo que, nesta pesquisa, serão chamadas UT1, UT2 e UT3, respectivamente.

Deste modo, identificou-se, em cada um dos Manuais, a qual unidade temática pertencia o conteúdo de Geociências. Foi calculado o percentual de conteúdos por unidade temática no Livro do Aluno (LA), nas Orientações Didáticas (OD) e no Manual do Professor.

Todos os cálculos foram feitos tanto individualmente, levando-se em conta o universo de cada Manual do Professor por ano do Ensino Fundamental I, como, ao final, foi feito somando-se os valores de todos os Manuais, para obter uma resposta que correspondesse a valores referentes a todo o Ensino Fundamental I.

\section{Etapa 3: Categorização do conteúdo Geociências}

A última etapa metodológica consistiu em sumarizar os conteúdos de Geociências identificados nos cinco manuais de acordo com as unidades temáticas propostas pela BNCC. Dessa forma foi feita uma síntese descritiva desses conteúdos dentro de cada uma dessas unidades temáticas, criando-se então categorias emergentes (BARDIN, 2011) a partir desses conteúdos. 
Figura 5 - Fases percorridas na Etapa 2: quantificação do conteúdo Geociências
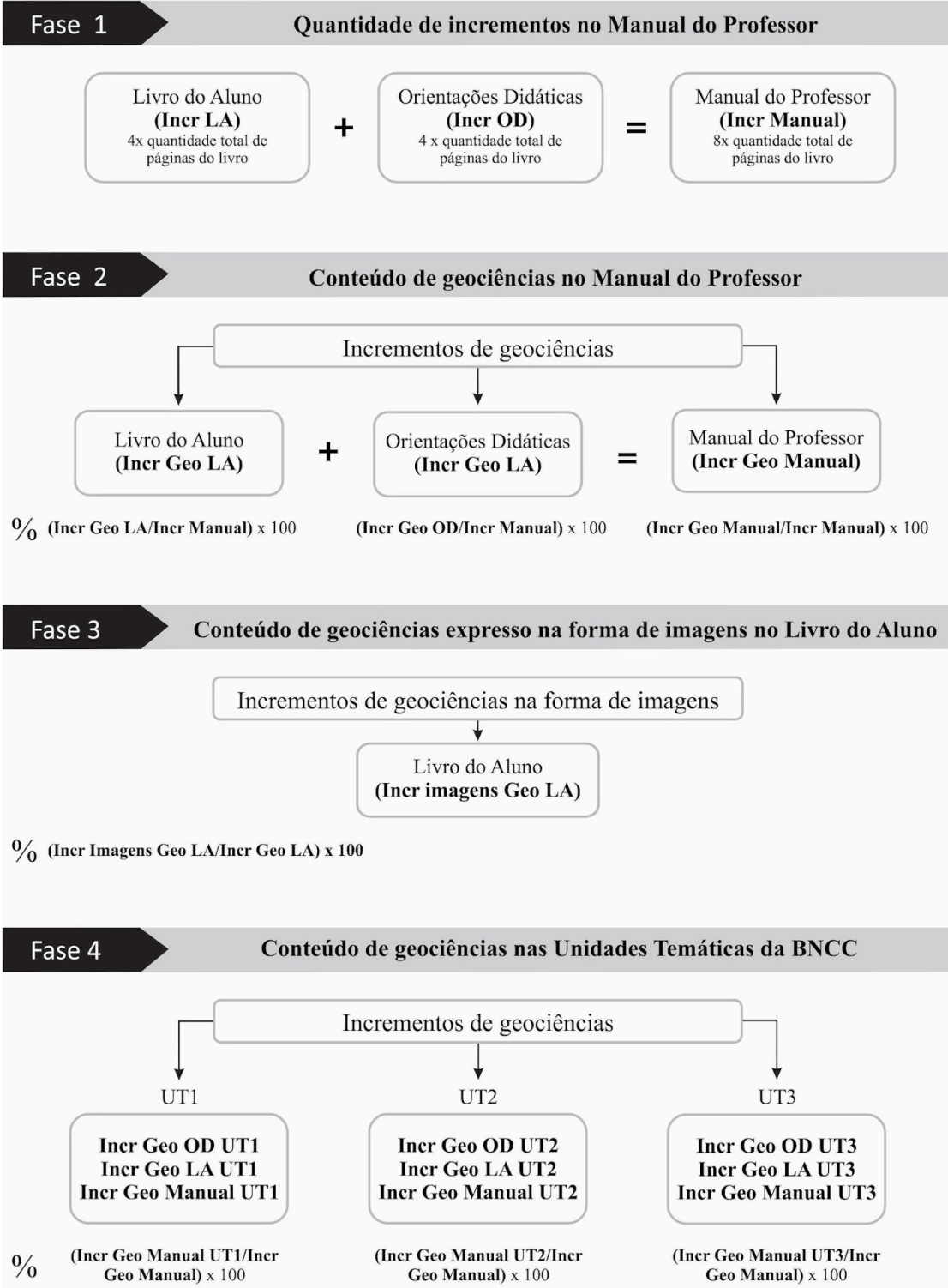

Nota: Fase 1: Quantidade de incrementos de Geociências no Manual do Professor. Fase 2: quantidade e porcentagem de incrementos de Geociências considerando-se o Livro do Aluno e as Orientações Didáticas que, somados, correspondem ao Manual do Professor. Fase 3: o conteúdo de Geociências contido nos manuais na forma de imagens. Para este caso, o cálculo de porcentagem considerou apenas o Livro do Aluno, pois não foram localizadas imagens de Geociências nas Orientações Didáticas. Fase 4: conteúdo de Geociências conforme cada unidade temática proposta pela BNCC para o ensino de Ciências.

Fonte: elaborada pelas autoras.

\section{Resultados e Discussão}

Os resultados dividem-se em quantificação dos conteúdos de Geociências nos manuais, bem como uma síntese descritiva e categorização dos mesmos.

\section{Conteúdos de Geociências nos Manuais do Professor}

A quantificação dos conteúdos de Geociências nos Manuais do Professor analisados, considerando-se os espaços destinados ao Livro do Aluno e às Orientações Didáticas, conforme pode ser visto na Tabela 1, evidencia que o Manual com mais conteúdos de Geociências é o AK 3 (32,38\%), enquanto o AK 1 apresentou o menor valor (7,4\%). 
Apesar dos estudos já realizados na área centrarem esforços no Ensino Fundamental II, à luz do trazido por Bacci, Oliveira e Pommer (2009), este trabalho evidenciou que, também no Ensino Fundamental I, os conteúdos de Geociências se apresentam de forma relevante, tendo constatado, a partir dos manuais analisados, que um percentual de $18,13 \%$ dos conteúdos abordados é de Geociências.

Observando-se a Tabela 1, verifica-se que Incr Geo LA é sempre maior que Incr Geo OD, ou seja, em todos os Manuais, os conteúdos de Geociências se encontram, em maior quantidade, expostos no Livro do Aluno, porém associados às recomendações contidas nas Orientações Didáticas.

Tabela 1 - Conteúdo de Geociências nos Manuais do Professor analisados, considerando-se os espaços destinados às Orientações Didáticas (OD) e ao Livro do Aluno (LA). [Em negrito e em itálico: maiores e menores valores por coluna, respectivamente]

\begin{tabular}{|c|c|c|c|c|c|c|c|c|}
\hline \multicolumn{5}{|c|}{ Manual do Professor (OD+LA) } & \multicolumn{4}{|c|}{ Livro do Aluno (LA) } \\
\hline & $\mathrm{Pg}$ & Incr Manual & Incr $C$ & Manual & Incr Geo OD & Incr Geo em & Incr Geo LA & Incr Geo em \\
\hline Manual por ano & un & un & un & $\%$ & un & $\%$ & un & $\%$ \\
\hline AK 1 & 84 & 672 & 50 & 7,40 & 20 & 3,00 & 30 & 4,50 \\
\hline AK 2 & 102 & 816 & 98 & 12,00 & 38 & 4,60 & 60 & 7,35 \\
\hline AK 3 & 132 & 1056 & 342 & 32,38 & 127 & 12,02 & 215 & 20,35 \\
\hline AK 4 & 164 & 1312 & 175 & 13,33 & 52 & 3,96 & 123 & 9,37 \\
\hline AK 5 & 166 & 1328 & 275 & 20,70 & 85 & 6,40 & 190 & 14,30 \\
\hline Total & 648 & 5184 & 940 & 18,13 & 322 & 6,21 & 618 & 11,92 \\
\hline
\end{tabular}

Nota: AK 1: Akpalô $1^{\circ}$ ano; AK 2: Akpalô $2^{\circ}$ ano; AK 3: Akpalô $3^{\circ}$ ano; AK 4: Akpalô 4 ano; AK 5: Akpalô 5ªno; Pg: quantidade de páginas do Manual do Professor (pg); Incr Manual: quantidade de incrementos (Incr) no Manual do Professor; Incr Geo Manual: total de incrementos de Geociências no Manual do Professor (OD+LA) em quantidade e porcentagem; Incr Geo OD: quantidade de incrementos de Geociências nas Orientações Didáticas; Incr Geo em OD/manual: porcentagem de incrementos de Geociências nas Orientações Didáticas em relação ao Manual; Incr Geo LA: quantidade de incrementos de Geociências no Livro do Aluno; Incr Geo em LA/manual: porcentagem de incrementos de Geociências no Livro do Aluno em relação ao Manual.

Fonte: elaborada pelas autoras.

Do total de conteúdos de Geociências nos cinco Manuais do Professor analisados (Incr Geo Manual - AK 1 a AK 5), 65,7\% estão no Livro do Aluno e 34,3\% estão nas Orientações Didáticas, tendo sido identificado que conceitos definidos com maior rigor científico se encontram localizados nesse último espaço, uma vez que não sendo o professor nessa fase da educação necessariamente especialista nos conteúdos que ministra, os manuais do professor recorrentemente trazem em suas orientações didáticas também conteúdo para fundamentar o conhecimento do próprio professor. Ao mesmo tempo em que essa ferramenta auxilia, pode também limitar a busca acerca do tema, uma vez que, como exposto por Silva (2012), esse pode ser, muitas vezes, o único material de consulta que o professor utiliza para fundamentar sua aula. Este aspecto reforça a importância de especialistas atuarem na organização de materiais complementares aos LD's.

As imagens adquiriram relevância na pesquisa durante a fase de pré-análise dos manuais, por isso, a Tabela 2 mostra a quantidade de conteúdo de Geociências que é expresso na forma de imagens nos manuais analisados. Como para os conteúdos de Geociências não foram encontradas imagens nas Orientações Didáticas, na Tabela 2 encontram-se os conteúdos de Geociências expressos na forma de imagens, levando-se em consideração 
apenas o Livro do Aluno. Foi visto que, em todos os livros analisados, a representação dos conteúdos de Geociências na forma de imagens superou 36\%. O AK 3, apesar de ser o livro que abarca mais conteúdos geocientíficos, foi o que teve uma menor representação desses em forma de imagens, tendo sido calculado 36,6\%. Quanto ao AK 2, livro que menos trabalha conteúdos geocientíficos, foi o que teve maior representação destes em forma de imagens, chegando a 46,7\%. Finalmente, para todos os Livros do Aluno, foi constatado que as imagens representam 39,32\% dos conteúdos de Geociências, sendo observada qualitativamente sua representação nas mais diversas formas (fotografias, esquemas, ilustrações), destacando-se, em negrito e em itálico, os maiores e menores valores em percentagem, respectivamente.

Por se tratar de uma faixa etária infantil, idade estimada entre 6 e 10 anos, a expressiva utilização de imagens, principalmente no Livro do Aluno, conforme foi visto, auxilia a exposição do conteúdo e que, segundo Pavão e Freitas (2008), é um recurso que o professor pode utilizar para exercitar a capacidade de investigação das crianças, explorando, por essa via, a maneira como elas interpretam as imagens e, por conseguinte, o próprio mundo. Desse modo, mesmo imagens que possuam caráter ilustrativo, se forem exploradas pelo professor com questionamentos estimulando a investigação e reforço da aprendizagem, constituem importante ferramenta no processo do ensino.

Tabela 2 - Conteúdos de Geociências expressos na forma de imagens no livro do aluno. [Em negrito e em itálico: maiores e menores valores em percentagem, respectivamente]

\begin{tabular}{lccc}
\hline & Incr Geo LA & $\begin{array}{c}\text { Incr Imagens } \\
\text { Geo LA }\end{array}$ & $\begin{array}{c}\text { Conteúdo de Geociências } \\
\text { expresso na forma de imagens } \\
\text { no livro do aluno }\end{array}$ \\
\hline Manual por ano & un & un & $\%$ \\
\hline AK 1 & 30 & 14 & 46,6 \\
AK 2 & 60 & 28 & $\mathbf{4 6 , 7}$ \\
AK 3 & 215 & 78 & 36,3 \\
AK 4 & 123 & 47 & 38,2 \\
AK 5 & 190 & 76 & 40,0 \\
\hline Total & 618 & 243 & 39,3 \\
\hline
\end{tabular}

Nota: AK 1: Akpalô 1º ano; AK 2: Akpalô $2^{\circ}$ ano; AK 3: Akpalô $3^{\circ}$ ano; AK 4: Akpalô 4a ano; AK 5: Akpalô $5^{\circ}$ ano; Incr Geo LA: quantidade de incrementos de Geociências no Livro do Aluno; Incr Imagens Geo LA: quantidade de incrementos referentes às imagens com conteúdo de Geociências no Livro do Aluno.

Fonte: elaborada pelas autoras.

A Tabela 3 evidencia a quantidade de conteúdos de Geociências, tanto em unidades de incrementos, como em percentagem, dentro das unidades temáticas propostas pela BNCC, considerando-se também a quantidade desses conteúdos nas Orientações Didáticas e no Livro do Aluno.

Constatou-se que $79,0 \%$ dos conteúdos de Geociências estão inseridos na unidade temática Terra e Universo, 14,4\% na unidade temática Matéria e Energia e 6,6\% na unidade temática Vida e Evolução. À exceção do manual AK 2, que apresentou 54,1\% dos conteúdos de Geociências inseridos na unidade temática Vida e Evolução, todos os demais manuais apresentaram maior percentual de conteúdos de Geociências na unidade temática Terra e Universo. 
Tabela 3 - Distribuição de conteúdos de Geociências, tanto em unidades de incrementos, como em porcentagem, dentro das unidades temáticas propostas pela BNCC

\begin{tabular}{|c|c|c|c|c|c|c|c|c|c|c|c|c|c|c|c|c|c|c|}
\hline \multicolumn{19}{|c|}{ Unidades Temáticas } \\
\hline \multicolumn{7}{|c|}{ Matéria e Energia (UT1) } & \multicolumn{6}{|c|}{ Vida e Evolução (UT2) } & \multicolumn{6}{|c|}{ Terra e Universo (UT3) } \\
\hline & \multicolumn{2}{|c|}{$\begin{array}{l}\text { Incr Geo } \\
\text { OD UT1 }\end{array}$} & \multicolumn{2}{|c|}{$\begin{array}{l}\text { Incr Geo } \\
\text { LA UT1 }\end{array}$} & \multicolumn{2}{|c|}{$\begin{array}{c}\text { Incr Geo } \\
\text { Manual } \\
\text { UT1 }\end{array}$} & \multicolumn{2}{|c|}{$\begin{array}{l}\text { Incr Geo } \\
\text { OD UT2 }\end{array}$} & \multicolumn{2}{|c|}{$\begin{array}{l}\text { Incr Geo } \\
\text { LA UT2 }\end{array}$} & \multicolumn{2}{|c|}{$\begin{array}{c}\text { Incr Geo } \\
\text { Manual } \\
\text { UT2 }\end{array}$} & \multicolumn{2}{|c|}{$\begin{array}{l}\text { Incr Geo } \\
\text { OD UT3 }\end{array}$} & \multicolumn{2}{|c|}{$\begin{array}{c}\text { Incr Geo LA } \\
\text { UT3 }\end{array}$} & \multicolumn{2}{|c|}{$\begin{array}{c}\text { Incr Geo } \\
\text { Manual } \\
\text { UT3 }\end{array}$} \\
\hline Manual & un & $\%$ & un & $\%$ & un & $\%$ & un & $\%$ & un & $\%$ & un & $\%$ & un & $\%$ & un & $\%$ & un & $\%$ \\
\hline AK 1 & 8 & 16,0 & 10 & 20 & 18 & 36,00 & - & - & - & - & & - & 12 & 24 & 20 & 40 & 32 & 64,00 \\
\hline AK 2 & - & - & 3 & 3,06 & 3 & 3,06 & 24 & 24,48 & 29 & 29,59 & 53 & 54,08 & 14 & 14,28 & 28 & 28,57 & 42 & 42,85 \\
\hline AK 3 & 5 & 1,46 & 9 & 2,63 & 14 & 4,09 & - & - & - & - & & - & 122 & 35,67 & 206 & 60,23 & 32,8 & 95,90 \\
\hline AK 4 & 2 & 1,14 & 9 & 5,14 & 11 & 6,28 & 4 & 2,28 & 5 & 2,85 & 9 & 5,14 & 46 & 26,28 & 109 & 62,28 & 155 & 88,57 \\
\hline AK 5 & 23 & 8,36 & 67 & 24,36 & 90 & 32,72 & - & - & - & - & & - & 62 & 22,54 & 123 & 44,72 & 185 & 67,27 \\
\hline Total & 38 & 4,0 & 98 & 10,4 & 136 & 14,4 & 28 & 3,0 & 34 & 3,6 & 62 & 6,6 & 256 & 27,2 & 486 & 51,7 & 742 & 79 \\
\hline $\begin{array}{l}\text { Total nos } \\
\text { Manuais }\end{array}$ & \multicolumn{6}{|c|}{$14,4 \%$} & \multicolumn{6}{|c|}{$6,6 \%$} & \multicolumn{6}{|c|}{$79 \%$} \\
\hline
\end{tabular}

Nota: AK 1: Akpalô $1^{\circ}$ ano; AK 2: Akpalô 20 ano; AK 3: Akpalô 3ano; AK 4: Akpalô 4o ano; AK 5: Akpalô $5^{\circ}$ ano. As unidades temáticas estão representadas nas três maiores colunas. Incr Geo OD UT1, Incr Geo OD UT2 e Incr Geo OD UT3: quantidade de incrementos, em número e em porcentagem, dos conteúdos de Geociências referentes às UT1, UT2 e UT3, respectivamente, contidas nas Orientações Didáticas; Incr Geo LA UT1, Incr Geo LA UT2 e Incr Geo LA UT3: quantidade de incrementos, em número e em porcentagem, dos conteúdos de Geociências referentes às UT1, UT2 e UT3, respectivamente, contidos no Livro do Aluno; Incr Geo Manual (OD + LA) UT1, Incr Geo Manual (OD + LA) UT2 e Incr Geo Manual (OD + LA) UT3: quantidade de incrementos, em número e em porcentagem, dos conteúdos de Geociências referentes às UT1, UT2 e UT3, respectivamente, contidos no Manual do Professor.

Fonte: elaborada pelas autoras.

\section{Descrição e categorização dos conteúdos de Geociências nos Manuais do Professor}

Primeiro, é trazida uma síntese descritiva dos conteúdos de Geociências que foram identificados e sua alocação dentro de cada unidade temática proposta pela BNCC, estabelecida conforme as habilidades e objetos de conhecimento propostos no referido documento. Logo após, pautando-se nos conteúdos expostos, são trazidas categorias que sumarizam os temas centrais de Geociências trabalhados ao longo do Ensino Fundamental I, nos livros de Ciências, coleção Akpalô.

\section{UT1: Matéria e Energia}

Por ser a Ciência do Sistema Terra, como dito por Piranha e Carneiro (2009), integradora das diferentes esferas em que a matéria se organiza e nas quais todas as formas de energia provocam mudanças à medida que são permutadas, é de se esperar que a unidade temática Matéria e Energia abarque conteúdos de Geociências.

Foram localizados conteúdos de Geociências inseridos nessa unidade temática em todos os manuais analisados. No AK 1, os conteúdos trabalhados relacionaram-se à questão dos materiais que são usados no dia a dia, mencionando alguns elementos geológicos, como os tijolos de argila e os metais. No AK 2, materiais voltam a ser abordados, acrescidos de suas propriedades. No AK 3, o tema relacionado às Geociências foi o Sol como fonte natural de luz. O AK 4 traz as mudanças no estado físico da água, utilizando o ciclo hidrológico da água como exemplo e as diferentes formas de encontrar água na natureza (geleiras, rios, lagos, oceanos, atmosfera). Por fim, o AK 5 retoma o conteúdo de água incluindo informações 
sobre águas subterrâneas e sua importância enquanto reservatório de água do planeta. Solo e impactos ambientais são também abordados, bem como é feita a diferenciação entre solo e rocha e mineral e minério.

\section{UT2: Vida e Evolução}

Foi encontrado conteúdo de Geociências dentro dessa unidade temática apenas no AK 2 e AK 4. No AK 2, que apresentou maior parte dos conteúdos de Geociências contidos nessa unidade temática $(54,1 \%)$, foram trabalhados os componentes do ambiente, diferindoos entre componentes vivos e componentes não vivos. A água, o solo, o ar e a luz do sol constituem os componentes não vivos do ambiente. Estes elementos são alvo do estudo das Geociências e foram neste manual, abordados, sobretudo, pela perspectiva da importância que tais elementos têm para que seja possível a vida na Terra e da dependência que os seres vivos têm desses elementos. Diferenciações entre ambientes aquáticos e terrestres também foram trabalhadas. Este volume trouxe termos como rocha e granito, ao afirmar que estes são componentes não vivos do ambiente. No AK 4, é reforçada a importância do Sol como fonte de calor e energia, mostrando o seu papel dentro da cadeia alimentar. O ambiente dos manguezais é definido baseado em sua distribuição espacial ao longo da costa e sua relação com o movimento das marés.

\section{UT3: Terra e Universo}

Esta foi a unidade temática que mais concentrou conteúdos de Geociências. Foram localizados conteúdos de Geociências inseridos nessa unidade temática em todos os manuais analisados, tendo relevante parcela dos conteúdos tratado temas relacionados ao universo e aos astros, ao que Compiani (2018) já havia tecido comentários, afirmando ser inegável o aumento dos conhecimentos de astronomia na versão aprovada da BNCC.

No AK 1 foi trabalhada a passagem do tempo no ambiente, o dia relacionado à presença do Sol no céu e à claridade, e a noite relacionada à presença da Lua e das estrelas. No AK 2, o Sol é estudado a partir da definição de sombras, que ajudam a explicar o movimento aparente do Sol no céu ao longo do dia. Inicia-se a abordagem do nascer do sol ao leste e do pôr do sol a oeste. Em AK 3, 95,9\% do conteúdo de Geociências refere-se a esta unidade temática, trazendo a definição de astro, estrelas e da Lua. A Lua é estudada conforme as suas fases. Retoma-se o conteúdo de passagem do tempo, sendo agora mais explícita a sua relação com o movimento da Terra tendo o Sol como referencial, com a introdução e definição do conceito de rotação. As representações da Terra em globos e mapas e, a partir deles, a distribuição dos oceanos e continentes são introduzidas. Os componentes não vivos que em AK 2 foram trabalhados em Vida e Evolução são, em AK 3, enquadrados na unidade temática Terra e Universo. Nesta parte, trabalha-se o conceito de rocha, por exemplo.

No AK 4 são aprofundados os conceitos dos movimentos de rotação e translação. O Sol é estudado também nos conteúdos sobre orientação geográfica, trazendo a relação entre os pontos cardeais e a rosa dos ventos. O calendário é novamente explicado, relacionando-se o calendário solar (gregoriano) com o movimento de translação. O sistema solar é explorado e os planetas são apresentados, demonstrando-se a relação de tamanho entre eles (escala). 0 conceito de órbita é definido. 
Por fim, no AK 5, há um enfoque especial na tecnologia utilizada para se estudar o espaço, como as lunetas, binóculos, telescópios, sondas espaciais. Conceitos como órbita são retomados para explicar como os satélites se mantêm no espaço. Cometas são definidos. Os movimentos dos astros são mais uma vez trabalhados, com os movimentos de translação e rotação e suas respectivas relações com os anos e os dias. O movimento de translação é também relacionado às estações do ano. As fases da Lua e o calendário são novamente abordados. As constelações foram estudadas, a exemplo de Escorpião, Órion e Cruzeiro do Sul.

\section{Categorias Emergentes}

Analisando a síntese descritiva dos conteúdos de Geociências, observa-se que o volume dos conteúdos se deu mais na repetição do que na pluralidade destes. Por meio da leitura do corpus da pesquisa, foram estabelecidas nove categorias emergentes, segundo os critérios de Bardin (2011), as quais representam também os temas centrais de Geociências estudados ao longo do Ensino Fundamental I, sendo elas: Sol como fonte de luz e energia, Materiais e suas propriedades, Ciclo hidrológico da água, Componentes não vivos do ambiente, Ambientes, Representações da Terra, Orientação geográfica, Movimento dos astros e suas implicações e Tecnologia espacial.

Ao buscar espaços nos quais seja possível trabalhar os conteúdos programáticos na tentativa de relacioná-los ao espaço e às questões de vivência dos educandos, são variadas as possibilidades. Para os manuais analisados, o enfoque no que se refere à origem dos materiais, mesmo que esse conteúdo seja contemplado pela Geografia (não avaliada no presente artigo) e mais aprofundado no Ensino Fundamental II, a introdução à origem desses materiais de modo complementar aos manuais de Ciências favorece um entendimento mais integrado. Essa interface do uso e das propriedades com a origem dos materiais possibilita uma compreensão mais sistêmica do planeta, reforçando a relação dos materiais geológicos como matéria-prima, abrindo espaços para o debate quanto à prevenção de problemas ambientais. Neste aspecto, cabem relevantes contribuições das Geociências a nível local, podendo ser trabalhados exemplos de elementos geológicos que são utilizados como recursos na região de vivência dos alunos.

Os conteúdos trazidos na UT2, apesar de terem representado a menor percentagem de conteúdos de Geociências (6,6\%), abarcam temas relevantes para serem tratados a nível local e/ou regional. Por ter sido trabalhada nessa unidade a questão dos componentes não vivos do ambiente, tem-se uma explícita abertura para desenvolver atividades em ambientes externos às salas de aula, sobretudo os ambientes naturais. Embora isso já seja sugerido nas orientações didáticas dos manuais, a formação dos professores pode ser um agravante frente ao desenvolvimento dos assuntos geocientíficos, como trazido por Piranha (2006), ao mencionar que:

[...] os professores das disciplinas de Ciências e Geografia são formados, em geral, em cursos de licenciatura em Biologia, Geografia, Física e Química, não sendo a estes facultados suficientes meios de incorporarem uma fundamentação conceitual básica de Geociências, que Ihes confira a segurança e desenvoltura necessárias para trabalhar, a contento, os conceitos envolvidos. (PIRANHA, 2006, p. 18). 
Outro tema que chamou atenção, principalmente pela relevante presença nos Manuais, foi o movimento dos astros e suas implicações, presente na UT3. Por tratar-se de conceitos de larga escala, o estudo do universo nesse sentido limita os estudos locais/regionais, já que pouco diferem a nível nacional; porém, constitui um importante espaço para incitar o senso de investigação dos alunos, uma vez que na infância a curiosidade está mais aguçada e os temas relacionados às Geociências despertam muito interesse (BACCl; OLIVEIRA, POMMER, 2009). Logo, por tratar-se de tema que desperta a curiosidade das crianças e que a compreensão é permitida por meio da observação do dia a dia, este conteúdo pode ser largamente explorado em atividades práticas, experimentais e de campo.

\section{Conclusão}

Constatou-se que o total de conteúdos de Geociências presentes nos cinco manuais da coleção Akpalô representaram 18,13\% dos conteúdos estudados, reforçando a presença desses conteúdos no Ensino Fundamental I. Analisando estes conteúdos, conforme o que é proposto pela BNCC, constatou-se também que os conteúdos de Geociências perpassam pelos objetos de conhecimento contido nas três unidades temáticas propostas pelo referido documento para o ensino de Ciências. Os temas centrais abordados podem ser sumarizados nas categorias emergentes definidas por este trabalho: Sol como fonte de luz e energia, Materiais e suas propriedades, Ciclo hidrológico da água, Componentes não vivos do ambiente, Ambientes, Representações da Terra, Orientação geográfica, Movimento dos astros e suas implicações e Tecnologia espacial.

Assim, identificaram-se espaços cabíveis para complementações com conteúdo geocientífico a partir da contextualização desses conteúdos com elementos de vivência dos alunos, partindo-se das peculiaridades locais e regionais. Evidencia-se também o Ensino Fundamental I como um campo para pesquisas nesta temática e a importância de especialistas atuarem na organização de materiais complementares aos LD's.

Outra questão que adquiriu relevância na pesquisa foram as imagens, tendo sido constatado que estas representaram 39,3\% dos conteúdos de Geociências; verifica-se a necessidade de investigação, em trabalhos futuros, da natureza que estas possuem. Outra sugestão é uma análise de conteúdo sob a ótica da cientificidade dos conceitos, uma vez que o fato de o Ensino Fundamental I utilizar uma linguagem mais simples, não implica em reproduzir informações equivocadas e até mesmo errôneas prejudicando a qualidade e construção do conteúdo, o que é indesejável.

\section{Agradecimentos}

Agradecemos à Coordenação de Aperfeiçoamento de Pessoal de Nível Superior (Capes), pelo financiamento da bolsa de mestrado que tornou essa pesquisa possível (processo 88882.375317/2019-01).

Agradecemos também à Secretaria Municipal de Educação de Natal, na pessoa de Vânia Lúcia de Lima, pela atenção e informações que nos auxiliaram a entender a dinâmica do ensino e escolha dos livros didáticos na rede municipal de Natal, bem como a professora Dalvani de Almeida da Escola Municipal Angélica de Almeida Moura pelo empréstimo dos livros analisados. 


\section{Referências}

BACCI, D. C. Ensino de geociências no contexto escolar: múltiplas relações com a educação ambiental. In: BACCI, D. C. Geociências e educação ambiental. Curitiba: Ponto Vital, 2015. p. 129-151.

BACCI, D. C. BOGGIANI, P. C. Currículo do curso de licenciatura em geociências e educação ambiental LiGEA-USP: formação de professores com visão sistêmica do planeta Terra. In: BACCl, D. C. (org). Geociências e educação ambiental. Curitiba: Ponto Vital, 2015. p. 9-25.

BACCI, D, C. OLIVEIRA, L. POMMER, C. Contribuição da abordagem geocientífica no ensino fundamental: tempo geológico, origem do petróleo e mudanças ambientais. Enseñanza de las Ciencias, Barcelona, n. ext., p. 3459-3463, 2009.

BARDIN, L. Análise de conteúdo. Lisboa: Edições 70, 2011.

BERGQVIST, L. P. PRESTES, S. B. S. Kit paleontológico: um material didático com abordagem investigativa. Ciência \& Educação, Bauru, v. 20, n. 2, p. 345-357, 2014. DOI: https://doi. org/10.1590/1516-73132014000200006.

BIGAISKI, D. SOURIENT, L. Akpalô ciências. São Paulo: Editora do Brasil, 2017. (Coleção do $1^{\circ}$ ao $5^{\circ}$ ano do ensino fundamental).

BRASIL. Ministério da Educação. Base nacional comum curricular: ensino fundamental. Brasília: MEC, 2017.

BRASIL. [Constituição (1988)]. Constituição da República Federativa do Brasil. Brasília: Senado Federal, [1988]. Disponível em: http://www.senado.leg.br/atividade/const/constituicao-federal.asp\#/. Acesso em: 07 jun. 2019.

BRASIL. Lei no 9.394, de 20 de dezembro de 1996. Estabelece as diretrizes e bases da educação nacional. Diário Oficial da União, Brasília, 23 dez. 1996. Disponível em: http://www.planalto.gov.br/ ccivil_03/leis/I9394.htm. Acesso em: 21 set. 2020.

BRASIL. Secretaria de Educação Fundamental. Parâmetros curriculares nacionais: introdução aos parâmetros curriculares nacionais. Brasília: MEC: SEF, 1997.

CARNEIRO, C. D. R.; SIGNORETTI, V. V. A carência de conteúdos de geociências no currículo básico comum de geografia do ensino fundamental em Minas Gerais. Geografia, Rio Claro, v. 33, n. 3, p. 467-484, 2008.

CARNEIRO, C. D. R.; TOLEDO, M. C. M; ALMEIDA, F. F. M. Dez motivos para a inclusão de temas de geologia na educação básica. Revista Brasileira de Geociências, São Paulo, v. 34, n. 4, p. 553-560, 2004. Disponível em: http://www.ppegeo.igc.usp.br/index.php/rbg/article/view/9787. Acesso em: 21 set. 2020.

CARNEIRO, M. H. S.; SANTOS, W. L. P.; MÓL, G. S. Livro didático inovador e professores: uma tensão a ser vencida. Ensaio, Belo Horizonte, v. 7, n. 2, p. 101-113, 2005. DOI: https://doi.org/10.1590/198321172005070204.

CARVALHO NETO, E. R. G. O livro didático e as teorias pedagógicas. Holos, Natal, v. 6, p. 402-414, 2015.

COMPIANI, M. Comparações entre a BNCC atual e a versão da consulta ampla, item ciências da natureza. Ciências em Foco, Campinas, v. 11, n. 1, jun. 2018.

COMPIANI, M. As geociências no ensino fundamental: um estudo de caso sobre o tema "a formação do universo". 1996. 224 f. Tese (Doutorado em Educação) - Faculdade de Educação, Universidade Estadual de Campinas, Campinas, 1996.

COMPIANI, M. Geologia/geociências no ensino fundamental e a formação de professores. Geologia USP, São Paulo, v. 3, p. 13-30, set. 2005. DOI: https://doi.org/10.11606/issn.2316-9087.v3i0p13-30. 
COMPIANI, M. Projeto geociências e a formação continuada de professores em exercício no ensino fundamental: reflexões e resultados finais. Zona Próxima, Barranquilla, n. 3, p. 26-49, nov. 2002.

GUIMARÃES E. M. A contribuição da geologia na construção de um padrão de referência do mundo físico na educação básica. Revista Brasileira de Geociências, São Paulo, v. 34, n. 1, p. 87-94, 2004.

PAVÃO, A. C.; FREITAS, D. Quanta ciência há no ensino de ciências. São Carlos: EdUFSCar, 2008.

PEREZ, C. P.; ANDRADE L. C.; RODRIGUES M. F. Desvendando as geociências: a alfabetização científica por meio de oficinas didáticas para alunos do ensino fundamental em PortoVelho, Rondônia. Terrae Didatica, Campinas, v. 11, n. 1, p. 42-51, 2015. DOI: https://doi.org/10.20396/td.v1111.8637309.

PIRANHA, J. M. O ensino de geologia como instrumento formador de uma cultura de sustentabilidade: o projeto geo-escola em São José do Rio Preto, SP. 2006. 222 f. Tese (Doutorado em Ciências) Instituto de Geociências, Universidade Estadual de Campinas, Campinas, 2006.

PIRANHA, J. M.; CARNEIRO, C. D. R. O ensino de geologia como instrumento formador de uma cultura de sustentabilidade. Revista Brasileira de Geociências, São Paulo, v. 9, n. 1, p. 129-137, mar. 2009.

PONTE, M. L.; PIRANHA, M. J. Estratégias e recursos educacionais para inserção das geociências na educação básica. Terrae Didatica, Campinas, v. 14, n. 4, p. 431-438, 2018. DOI: https://doi. org/10.20396/td.v14i4.8654193.

RUPPENTHAL, R.; SCHETINGER, M. R. C. O sistema respiratório nos livros didáticos de ciências das séries iniciais: uma análise do conteúdo, das imagens e atividades. Ciência \& Educação, Bauru, v. 19, n. 3, p. 617-632, 2013. DOI: https://doi.org/10.1590/S1516-73132013000300008.

SILVA, M. A. A Fetichização do livro didático no Brasil. Educação \& Realidade, Porto Alegre, v. 37, n. 3, p. 803-821, 2012.

TOMOTANI, J. V. SALVADOR, R. B. Análise do conteúdo de evolução em livros didáticos do ensino fundamental brasileiro. Pesquisa e Ensino em Ciências Exatas e da Natureza, Cajazeiras, v. 1, n. 1, p. 5-18. 2017.

VEXELS: open book illustration. [2020]. Disponível em: https://www.vexels.com/vectors/ preview/119651/open-book-illustration. Acesso em: 19 jul. 2019. 